\title{
How COVID-19 Pandemic Indirectly Affected Orthopedic Patients: A Case Report of a Rescue Treatment For a Proximal Humerus Nonunion
}

\author{
Panzera $\mathbf{R M}^{1}$, Reina $\mathbf{M}^{1}$, Nesta $\mathrm{F}^{1}$, Zattoni $\mathrm{G}^{2}$, Terragnoli $\mathrm{F}^{2}$, Benazzo $\mathrm{F}^{2}$ and Morea $\mathrm{V}^{2 *}$ \\ ${ }^{1}$ Università Cattolica del Sacro Cuore, Rome, Italy \\ ${ }^{2}$ Fondazione Poliambulanza, Brescia, Italy
}

*Corresponding author: Morea Vincenzo, Università Cattolica del Sacro Cuore, Rome, Italy

\begin{tabular}{|c|c|}
\hline ARTICLE INFO & ABSTRACT \\
\hline Received: 幽 September 16, 2021 & \multirow{5}{*}{$\begin{array}{l}\text { The management of proximal humerus fracture is often challenging for orthopedic } \\
\text { surgeons. Most of these fractures, in fact, occurs in old women with poor bone } \\
\text { quality. Risk of loosening or nonunion and risk of avascular necrosis of humeral head } \\
\text { is high, especially in four-parts fractures. We present a case of a } 69 \text {-year-old woman } \\
\text { with proximal humeral nonunion associated with a humeral head osteonecrosis. The } \\
\text { peculiarity of this case is that the patient had no follow-up for } 7 \text { months because of the } \\
\text { Covid-19 pandemic and the restrictions that resulted. We intend to describe how this } \\
\text { social situation forced us to change our strategy of treatment and to discuss how to face } \\
\text { the possible consequences in orthopedic practice. }\end{array}$} \\
\hline Published: September 23, 2021 & \\
\hline itation: Panzera RM, Reina M, Nesta F, & \\
\hline Iorea V, Zattoni G, et al., Environmental & \\
\hline $\begin{array}{l}\text { npacts and Control of Duststorms. Bi- } \\
\text { ned J Sci \& Tech Res 39(1)-2021. BJSTR. }\end{array}$ & \\
\hline
\end{tabular}
MS.ID.006231.

\section{Introduction}

Humeral fractures account for $5 \%$ to $8 \%$ of all fractures, whereas proximal humerus fractures represent the seventh most frequent fractures in adults $[1,2]$. Nonunion is a complication that occurs in $15 \%$ of all the humeral fractures [3] and its incidence increases in case of proximal humerus fracture [4]. Risk factors are advanced age, osteoporosis, obesity, smoking, alcoholism, and infection. Comminution and impaction of fractures and loss of fixation also contribute to the develop of nonunion [5,6]. This condition results in pain and loss of shoulder function. The management of proximal humerus nonunion is challenging and often the results are disappointing. Treatment of these kind of complications include open reduction and internal fixation with bone grafting but often it is an unsuccessful treatment resulting in bad clinical outcomes and further surgery is required. Other options are fixation with tension wires or with intramedullary nail [7].

These are optimal options for bone of good quality such as in young patients and with no signs of gleno-humeral arthritis. Shoulder arthroplasty is a reasonable option in case of proximal humerus nonunion associated with a rotator cuff damage and osteoporosis [8]. This case-report describes a proximal humeral nonunion in a 69-year-old woman who was first treated with an external fixation before the advent of COVID-19 pandemic. After removing the external fixator (EF), she was lost at follow-up because of the closure of our department during the Italian lockdown. She came back after seven months with pain and functional limitation. $\mathrm{X}$-Ray reported a nonunion of proximal humerus. In the end she underwent to reverse shoulder arthroplasty, recovering with a good result.

\section{Case Report}

A 69-year-old woman came to ER of Poliambulanza of Brescia in October 2019. X-rays were obtained. Fracture involved proximal humerus of the right, dominant, upper arm. The fracture was 11C3.1 according to AO classification. At first, the fracture was treated with an external. fixation using a Galaxy EF in the first twenty-four hours. The EF was removed after one month because of the loss of reduction with displacement of the fracture. Physio- 
kinesitherapy was indicated but she was unable to underwent to treatment. She was lost at follow -up for several months due to COVID-19 pandemic and the social limitations that resulted. After 7 months, Xrays showed a dislocated nonunion of proximal humerus with necrosis of the head. She complained shoulder pain with passive elevation of $40^{\circ}$ and scapular dyskinesia. In March 2021 she was listed for a reverse shoulder arthroplasty. During the surgery, Synovasure test and white blood cell count were performed: both tested negatives. A cemented trauma stem "Equinoxe" by Exactech number $8 \mathrm{~mm}$ was applied with a standard baseplate fixed with three screws of 26, 18, $18 \mathrm{~mm}$. External rotators were reinserted, and range of motion (ROM) was good at three months follow-up.

\section{Discussion}

The impact of COVID-19-related restrictions has resulted in changes in patients' healthcare and follow-up. During the pandemic, injured patients have experienced difficulties in receiving medical assistance, due to the lack of healthcare personnel and fear of contagion. Lombardy was the most affected region of Italy and orthopedic surgeons were involved in the emergency as other specialists $[9,10]$. Our level-2-trauma center in Brescia (Lombardy) went on admitting injured patients unceasingly, since several domestic accidents happened during that time, despite reports out of Italy noted a $65 \%$ reduction in trauma services provided for shoulder and elbow injuries during the time residents were asked to stay in the home [11]. One of the effects of the pandemic was the loss of follow-up of outpatients [12]. It is hypothesized that the main causes of this issue were the isolation and the fear of contagion in hospital environment [10] (Figure 1).

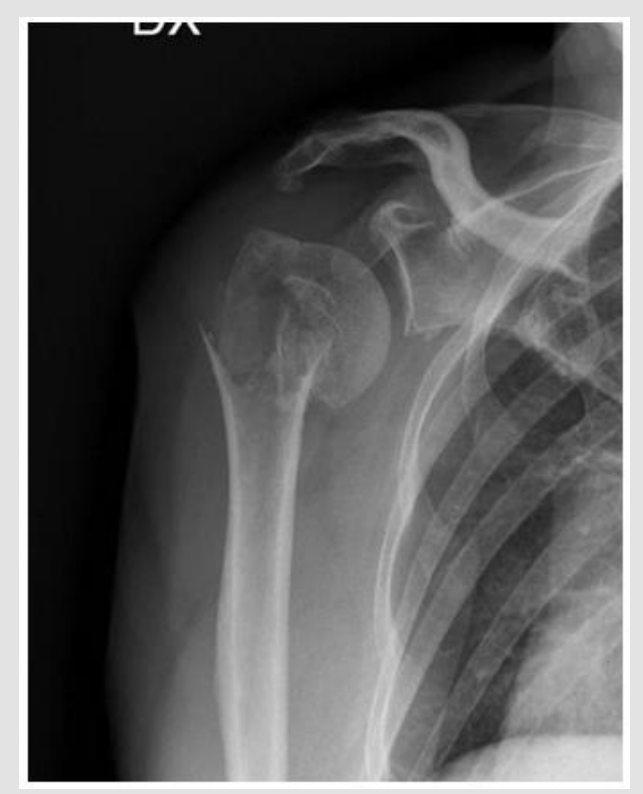

Figure 1: First radiograph showing comminuted and dislocated fracture.
Our case is a clear example of how COVID-19 pandemic and its resulting effects on social habits affected not only the timing, but the treatment itself of a patient who was not linked directly to Covid disease. The choice of implanting an external fixation device was based on the severity of fracture and on the general conditions of the patient. An open reduction and internal fixation (ORIF) were considered, but in the end it was discarded because of the high risk of avascular necrosis of the fragments [13]. To minimize the intraoperative jeopardy to the blood supply of the humeral head and avoid the complications of ORIF (blood loss, operating times, hardware migration requiring a second operation) [14], a minimally invasive first treatment was chosen. At one-month follow-up, the proximal pins presented migration and loss of grip, requiring the removing of the EF. Causes of the failure of this kind of treatment can be found primarily in the characteristics of the fracture and the bone, other than the technical issues [13,15] (Figures 2-6).

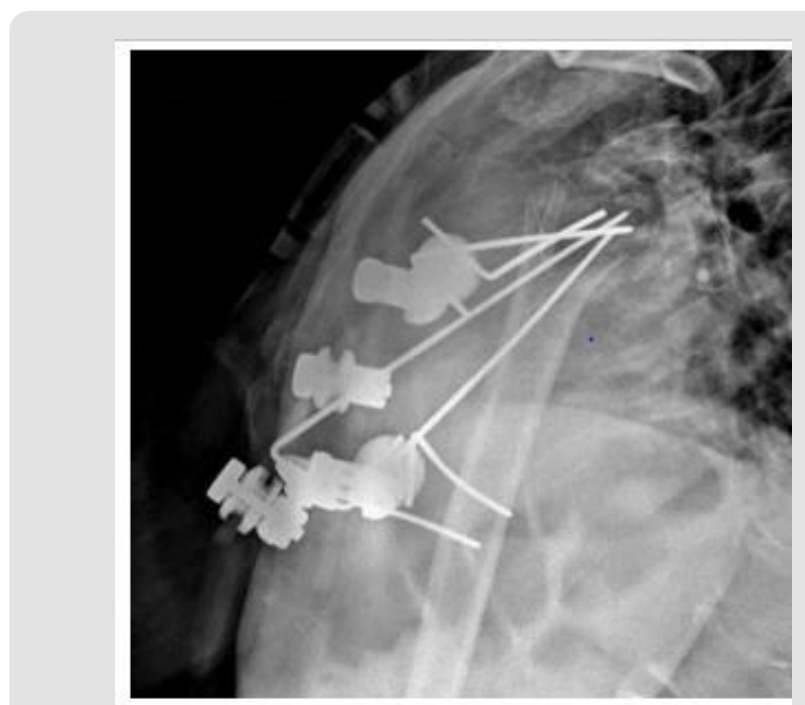

Figure 2: First treatment with EF.

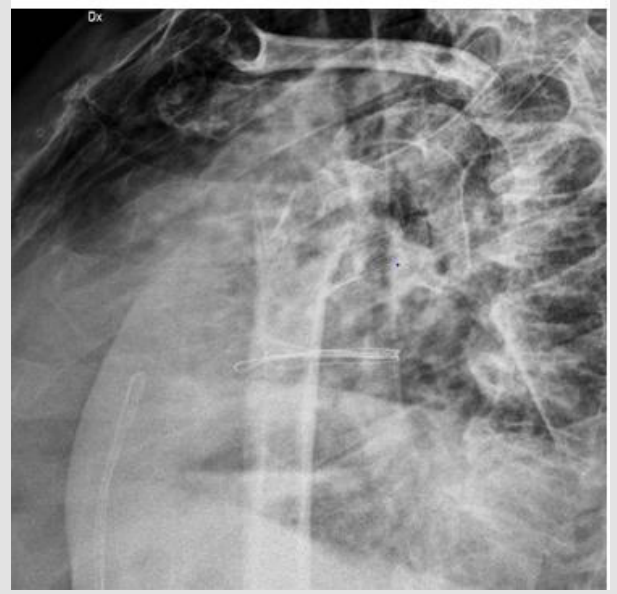

Figure 3: Partial loss of reduction after the removal of the EF. 


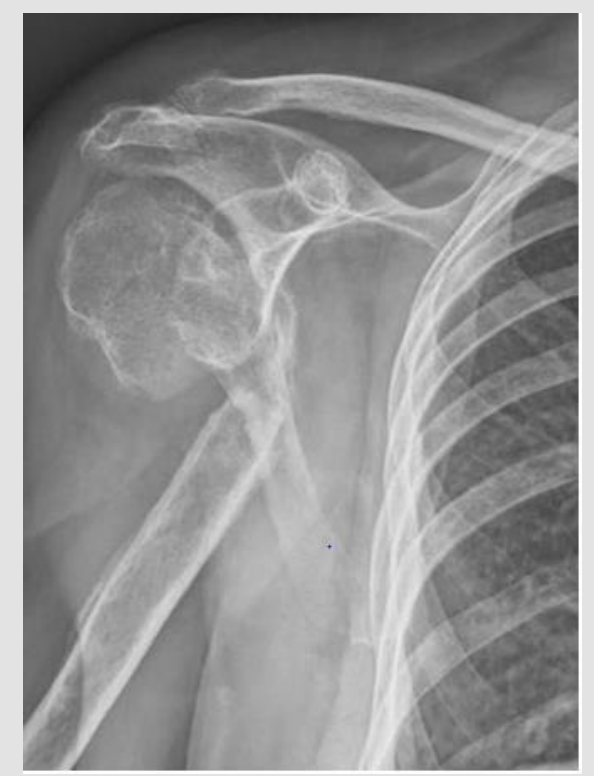

Figure 4: Nonunion and dislocation at 7 months after trauma.

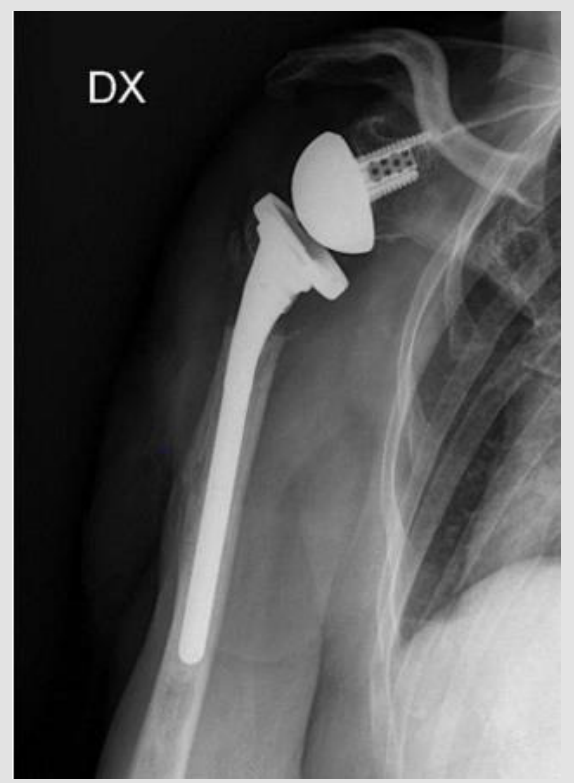

Figure 5: Final treatment.



Figure 6: Range of motion at 3 months after arthroplasty. 
Radiographic checks showed a partial loss of reduction and physio-kinesitherapy was indicated but she was unable to underwent to treatment because of the new social restrictions. Further radiographs showed gradual loss of reduction. Therefore, we started contemplating a definitive treatment by performing a ORIF with bone graft or a shoulder arthroplasty, but at that moment, the patient was lost at follow-up. Given the poor bone quality, after the removal of the EF, we would probably have implanted a hemiarthroplasty or a reverse prosthesis with a press-fit primary humeral stem fixation, considered an optimal choice because of the possible easier revision, decreased operative time, healing time, and resolution of the symptoms [16]. After 7 months, the patient came back to our department, suffering from pain and severe functional limitation, compounded by a preternatural movement of the joint. Radiographs showed evident dislocated nonunion with reabsorption of tuberosities and metaphysis.

Therefore, our choice has been to implant a reverse shoulder prosthesis with a cemented trauma stem "Equinoxe" by Exactech number $8 \mathrm{~mm}$. This choice involved several compromises like technical difficulties due to the severe bone loss and higher risks of dislocations, infections, nerve injuries and thromboembolism due to the use of cement, compared to an arthroplasty with a pressfit stem [17-20]. At three-month follow-up, the patient showed no pain and a sufficient function of the joint. Since the exact amount of loss to follow-up is not valuable, there is a chance that cases of nonunion in longstanding fractures like this could increase in the near future. Our experience shows that cemented stem fixation can be an important choice of treatment for these patients. Other strategies, like telemedicine, should be considered and eventually implemented to prevent this kind of consequences resulting from the pandemic [21-23].

\section{References}

1. Duralde XA, Flatow EL, Pollock RG, Nicholson GP, Self EB, et al. (1996) Operative treatment of nonunions of the surgical neck of the humerus. Journal of Shoulder and Elbow Surgery / American Shoulder and Elbow Surgeons 5(3): 169-180.

2. Roux A, Decroocq L, El Batti S, Bonnevialle N, Moineau G, et al. (2012) Epidemiology of proximal humerus fractures managed in a trauma center. Orthop Traumatol Surg Res 98(6): 715-719.

3. Wenzl ME, Porté Thomas, Fuchs Stefan (2003) Verfahren zur rekonstruktion und osteosynthese von pseudarthrosen des humerus. Trauma Berufskrankh 5: s86-s91

4. Badman BL, Mighell M, Kalandiak SP (2009) Proximal humeral nonunions treated with fixed-angle locked plating and an intramedullary strut allograft. J Orthop Trauma 23(3): 173-179.

5. Dhar SA, Butt MF, Dar TA, Dar RA, Ali Z (2016) Management of humeral fracture nonunion in severe osteoporosis by a combination of locking plating and intramedullary fibular grafting. Chin J Traumatol 19(5): 298301.
6. Lanting B, MacDermid J, Drosdowech D, Faber KJ (2008) Proximal humeral fractures: a systematic review of treatment modalities. J Shoulder Elbow Surg 17(1): 42-54.

7. Volgas DA, Stannard JP, Alonso JE (2004) Nonunions of the Humerus. Clinical Orthopaedics and Related Research 419L: 46-50.

8. Pinkas D, Wanich TS, DePalma AA, Gruson KI (2014) Management of malunion of the proximal humerus: current concepts. J Am Acad Orthop Surg 22(8): 491502.

9. Grasselli G, Pesenti A, Cecconi M (2020) Critical Care Utilization for the COVID-19 Outbreak in Lombardy, Italy: Early Experience and Forecast During an Emergency Response. JAMA 323(16): 1545-1546.

10. Gumina S, Proietti R, Polizzotti G, Carbone S, Candela V (2020) The impact of COVID-19 on shoulder and elbow trauma: an Italian survey. J Shoulder Elbow Surg 29(9): 1737-1742.

11. Congiusta DV, Otero K, Ippolito J, Thomson J, Beebe KS (2020) A new role for orthopaedic surgeons: ongoing changes, lessons learned, and perspectives from a level I trauma center during the COVID-19 pandemic. J Shoulder Elbow Surg 29(10): 1951-1956.

12. Wong JSH, Cheung KMC (2020) Impact of COVID-19 on Orthopaedic and Trauma Service: An Epidemiological Study. J Bone Joint Surg Am 102(14): e80.

13. Zhang J, Ebraheim N, Lause GE (2012) Surgical treatment of proximal humeral fracture with external fixator. J Shoulder Elbow Surg 21(7): 882-886.

14. Maluta T, Amarossi A, Dorigotti A, Bagnis F, Samaila EM, et al. (2020) External fixation can be an option for proximal humerus fractures Neer 3-4. Acta Biomed 91(14-S): e2020017.

15. Mehta S, Chin M, Sanville J, Namdari S, Hast MW (2018) Calcar screw position in proximal humerus fracture fixation: Don't miss high! Injury 49(3): 624-629.

16. Uy M, Wang J, Horner NS, Bedi A, Leroux T, et al. (2019) Cemented humeral stem versus press-fit humeral stem in total shoulder arthroplasty: a systematic review and meta-analysis. Bone Joint J 101-B(9): 1107-1114.

17. Salesky MA, Grace TR, Feeley BT, Ma CB, Zhang AL (2018) Effects of cemented versus press-fit primary humeral stem fixation in the setting of revision shoulder arthroplasty. J Shoulder Elbow Surg 27(5): 801-807.

18. Phadnis J, Huang T, Watts A, Krishnan J, Bain GI (2016) Cemented or cementless humeral fixation in reverse total shoulder arthroplasty? a systematic review. Bone Joint J 98-B(1): 65-74.

19. Zafra M, Uceda P, Flores M, Carpintero P (2014) Reverse total shoulder replacement for nonunion of a fracture of the proximal humerus. Bone Joint J 96B(9): 1239-12343.

20. Edoardo Giovannetti de Sanctis, Amarildo Smakaj, Guido Zattoni, Flavio Terragnoli, Giulio Maccauro, Morea Vincenzo (2020) Acute Axillary Artery Thrombosis Following Reverse Total Shoulder Arthroplasty for Complex Humeral Head Fracture: A Case Report. Biomed J Sci \& Tech Res 32(3): 2020.

21. Lau BC, Wittstein JR, Anakwenze OA (2021) How Are Orthopaedic Sports Medicine Physicians Triaging Cases and Using Telehealth in Response to COVID-19? A Survey of AOSSM Membership. Orthop J Sports Med 9(3): 2325967121990929.

22. Bluman EM, Fury MS, Ready JE, Hornick JL, Weaver MJ (2020) Orthopedic telemedicine encounter during the COVID-19 pandemic: A cautionary tale. Trauma Case Rep 28: 100323.

23. Benazzo F, Rossi SMP, Maniscalco P, Moretti B, Vaienti E, et al. (2020) The orthopaedic and traumatology scenario during Covid-19 outbreak in Italy: chronicles of a silent war. Int Orthop 44(8): 1453-1459. 
ISSN: 2574-1241

DOI: 10.26717/BJSTR.2021.39.006231

Morea V. Biomed J Sci \& Tech Res

(c) (P) This work is licensed under Creative Commons Attribution 4.0 License

Submission Link: https://biomedres.us/submit-manuscript.php

$\begin{array}{ll}\text { BIOMEDICAL } & \begin{array}{l}\text { Assets of Publishing with us } \\ \text { RESEARCHES }\end{array} \\ \text { - Global archiving of articles } \\ \text { - Immediate, unrestricted online access } \\ \text { - Rigorous Peer Review Process } \\ \text { - Authors Retain Copyrights }\end{array}$

